\title{
Owen revisited: a reappraisal of morphology in evolutionary biology
}

\author{
Alessandro Minelli ${ }^{1} \&$ Frederick R. Schram ${ }^{2}$ \\ ${ }^{1}$ Department of Biology, University of Padua, Via Trieste 75, I-35121 Padua, Italy; ${ }^{2}$ Institute of \\ Systematics and Population Biology, University of Amsterdam, Box 94766, NL-1090 GT Amsterdam, \\ The Netherlands
}

Keywords: homology, phylotype, macroevolution, morphogenesis

\begin{abstract}
A new analysis within the framework of developmental genetics provides both raw data and theoretical support to the "old" morphology and suggests a new, more predictive, approach to the concept of homology. We distinguish between "positional homologues" and "structural homologues" as independent components of the more general concept of homology. We discuss some general patterns seen in the anatomy of animals and in their morphogenesis. Slack et al. (1993) advanced the concepts of the "zootype", a particular spatial pattern of gene expression, and the "phylotype", a particular stage of embryonic development that expresses the zootype. We build upon these concepts and expand them. This allows us to propose some additional phylotypes (arthrotype, cyclotype, platytype, malacotype, trimerotype) that may guide future investigations towards understanding the genesis of metazoan form.
\end{abstract}

\section{Zusammenfassung}

Eine neue Analyse im Rahmen der Entwicklungsmechanik liefert sowohl empirische Evidenz und theoretische Unterstützung für die "alte" Morphologie als auch ein Homologiekonzept mit mehr Aussagekraft. Wir unterscheiden Lagehomologie und strukturelle Homologie im Sinne zweier grundsätzlich verschiedener Teile eines allgemeinen Homologiekonzeptes. Wir besprechen einige verallgemeinerte Muster der tierischen Morphologie and Morphogenese. Wir erweitern die Konzepte des Zootypus und des Phylotypus (Slack et al., 1993) auch dadurch, daß wir einige weitere Phylotypi (Arthrotypus, Cyclotypus, Platytypus, Malacotypus, Trimerotypus) in schematischen Zügen vorschlagen.

\section{Introduction}

Just over 150 years ago, Owen (1843) introduced definitions of the concepts of homology ["The same organ in different animal species under every variety of form and function"] and analogy ["A part or organ in one animal species which has the same function as another part or organ in a different species"'] that formalized the approach of succeeding generations to comparative anatomy. At that time, analysis of form, the so-called Baupläne, already had a central role in the studies and discussions of animal relationships that had prevailed in biology since the last few decades of the eighteenth century (e.g., see Russell, 1916).

Nevertheless, this method of analysis placed constraints on making direct comparisons between taxa that researchers did not perceive as close relatives. We might even suggest that the very notion of phyla directly arose as taxonomic expressions of the major difficulties encountered in assessing homologies. The conceptual source of our current practice of subdividing the animal kingdom into major groups (viz., what we currently call phyla) arises, in fact, from Cuvier's (1817) establishment of his four embranchements (Vertebrata, Articulata, Mollusca, and Radiata). Cuvier regarded these body plans as not comparable with each other, and so the unique and separate status of "phyla" became ensconced in our tradition. In contrast to this, Geoffroy St.Hilaire (1818-22) kept extending comparisons between animals. He eventually moved to a position wherein a single type-plan related all animals, an approach that had wide significance at the time but which eventually went into eclipse.

Only recently has the science of systematics made more rigorous, cladistics attempts to deal with ani- 
mal phyla in a way that would allow formulation of testable hypotheses concerning evolutionary relationships. The first such attempt to deal cladistically with all animal phyla with a single data matrix (Schram, 1991; Meglitsch \& Schram, 1991) has triggered further efforts to expand the data base and to evaluate alternative explanations (Eernisse et al., 1992; Conway Morris, 1993).

\section{Morphology and developmental genetics}

The intellectual viewpoint developed from the French savants for the study of morphology originally occurred without any understanding of the genetic mechanisms that underlie the generation of anatomical form. Revealing these mechanisms has not come easily. In fact, discerning the exact role that genes play in the control of form has presented problems. Nevertheless, throughout the last decade we have made quantum leaps in our knowledge of the genetics of development (e.g., see Lawrence, 1992), which has lead to a heightened level of sophistication in understanding the genetic control of animal architecture. Jacobs (1990), from the viewpoint of paleontology, and Averof \& Akam (1993) and Slack et al. (1993), from the viewpoint of developmental genetics, now suggest that this growing understanding offers the prospect of redefining the concept of "Metazoa" and, as a result, reconceptualize what it means to be a particular kind or type of animal. Slack et al. (p. 490) suggest "that an animal is an organism that displays a particular spatial pattern of gene expression", a pattern which they term the "zootype". By this they mean that the process of ontogenetic development comes under a specific manner of maternal and zygotic genetic control that defines a specified set of polarities of a developing animal embryo. This control serves to effectively define not so much the specific structures as the overall architectural framework of the adult animal body, i.e., anterior/posterior, left/right, dorsal/ventral.

We can conceive of their zootype as a state that contains a specific array of genes, which generate chemical linear gradients extending throughout the zygote, collectively termed the "Hox cluster".
These gradients determine the primary polarity of the zygote. Without this polarity the gross architectural orientation of the embryo and the capacity to develop more specific structures within it would be impossible. Slack et al. regard the evolution of this control as the necessary first step that allowed the evolution of metazoans to begin. They then extend this concept further to postulate the "phylotype", i.e., a particular stage in embryonic development at which the zootype becomes manifest.

This hypothesis in fact parallels concepts that have begun to appear in print, derived from purely comparative morphological research (Emerson \& Scharm, 1990; Schram \& Emerson, 1991; Minelli, 1992). These latter authors have tried to build on other, broader generalizations concerning the ontogeny of shape as applicable to understanding major shifts in animal form in the evolution of animal Baupläne, both for metazoans as a whole (Gould, 1977; Alberch et al., 1979) and crustaceans specifically (Schram, 1986). Together these genetic and morphologic advances constitute a breakthrough that can now allow us to move towards some general theory of morphology within the framework of animal macroevolution. We suggest that rather than one single phylotype we must speak of a series of phylotypes that correspond to other complexes of genes, in concert with the Hox complex and their expression, that control more specific aspects of metazoan body architecture.

It now seems clear that the diagnostic features of adult structure, i.e., characters that we have traditionally used to define phyla, appear "relatively late" in ontogeny as well as phylogeny, and that these features do not reveal the most fundamental characteristics of a phylum's architecture. As an example, we have traditionally diagnosed Arthropoda as those animals that possess a segmented body, bearing jointed appendages, and enclosed in a chitinized cuticle. However, serious problems develop when considering anatomy at this level. Many highly respected authorities (e.g., D.T. Anderson, 1973; Manton, 1977), focusing strictly on matters of ontogeny, function, and the structural differences between major arthropod types, do not agree with the effectiveness of such a diagnosis and challenge the idea of arthropod monophyly. Many 
other authorities, focusing on the similarities among major arthropod types, of course dispute this (e.g., see Gupta, 1979; Wheeler et al., 1993).

A different approach to arthropod phylogeny has emerged recently that deals with broad patterns seen in arthropod Baupläne rather than specific elements of form. Schram \& Emerson (1991) recognized a fundamental organization of the arthropod body in which regional markers along the length of the body, which they termed "nodes", serve as foci for structural events, and these nodes occur across all major groups of arthropods. The analysis of Schram \& Emerson implied that factors other than just the traditional "diagnostic features" of segments, jointed limbs, and chitin serve as the most important aspects to defining an arthropod. Rather, the organization of the arthropod body into distinct regions marked by specific "hot spots", around which "segmental" events take place, determines with greater certainty an organism's status as an arthropod. Thus, arthropods evolved not so much by the process of imposing a pattern on the segments as they did by segmenting (or breaking up) the more fundamental patterns of the body regions. They conclude that the ancestor of the arthropods possessed a body broken into a series of body regions, with borders demarcated by "hot spots" whose locations were genetically determined (probably by overlapping gradients), rather than a uniform, long body composed of iterative segments.

\section{Positional versus structural homology}

The approach outlined above allows a readjustment of our understanding of homology in animals. Traditionally, comparative anatomists have interpreted a specific structure at a specific position on the body of a species as a homologue if it matched an identical or similarly developed structure at a corresponding place in another species. However, if genes control the expression of not only structure, but also position (e.g., if in arthropods the control of specific structures, such as segments proper or appendages, is different from the control of position, or body pattern), then we can distinguish between the homology of structures and the homol- ogy of position. In other words, we can homologize places or positions along a body, e.g., in arthropods linking nodes or hot spots across species groups.

If we can entertain this possibility, then we can also homologize the events or structures located at those hot spots even though they may appear quite dissimilar in form or function. For example, in millipedes (Diplopoda), the gonopore occurs on what can be regarded as the fifth segmental unit posterior to the head (i.e., in the posterior part of the second double segment following the collum). In male dragonflies, a secondary penis or clasper occurs on the second abdominal segment. Gonopores are in no way a structural homologue of secondary penes. However (Fig. 1), we can perceive the fifth postcollum segment of diplopods as a positional homologue of the second abdominal segment of insects. Furthermore, Arthropod Pattern Theory (Schram \& Emerson, 1991) postulates that this very hot spot in "myriapods" and insects corresponds to an identical position in the Bauplan of the crustaceans where a maxillipede can occur. Therefore, because of this homology of location, we can extend the comparison between diplopod gonopores, dragonfly secondary penes, and crustacean maxillipedes as positional homologues. In the phylogenetic sequence of unfolding genetic constraints on arthropod development, the control of position, i.e., pattern and place, through the action of some combination of gap, pair rule, and homoeotic genes preceeds the genetic and/or epigenetic control of specific structures. On the other hand, we can recognize special homologues if they occur in different positions without the need to imply something like genetic piracy (Roth, 1988).

\section{Some general principles in animal morphology}

Indeed, we now can set down some general principles derived from the discoveries of developmental genetics as well as from the work of comparative morphologists. Laying down these points may contribute towards a general theory of morphology, if you will, a theory of macroevolution by pattern as an adjunct to the more traditional theory of microevolution by process. 
A
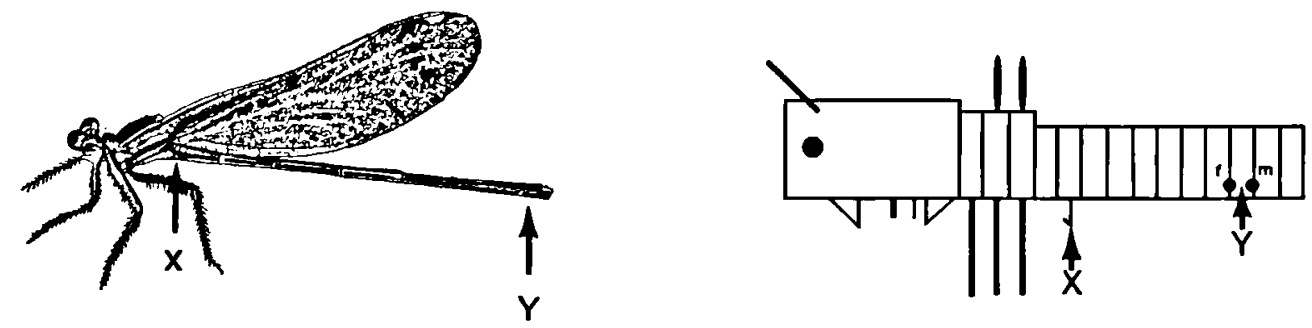

B
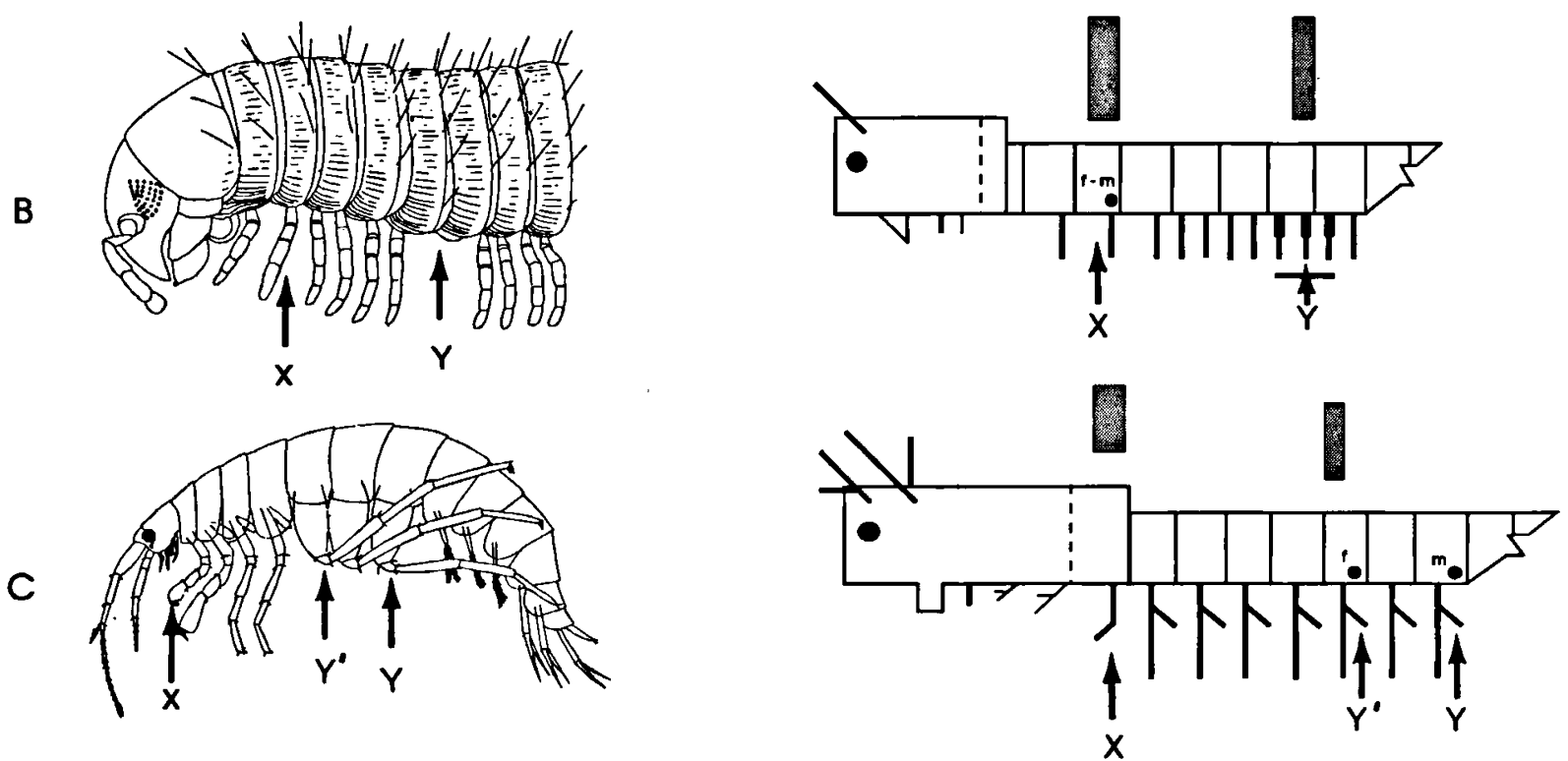

Fig. 1. Body features as different as the penis of a male dragonfly $(\mathrm{A}, \mathrm{X})$ and the genital opening of a millipede (B, X) can be regarded as positional homologues, in spite of the lack of structural homology between them. This homology possibly extends to a pair of maxillipedes of many crustaceans $(\mathrm{C}, \mathrm{X})$. Another example of positional homology is possibly given in the same animals, i.e., the gonopods of male juliform millipedes and the genital openings of dragonflies and crustaceans ( $Y$ in the figures on the left, $f$ (female opening) and $\mathrm{m}$ (male opening) in the sketch drawings on the right). Vertical bars indicate approximate levels of the nodes of Arthropod Pattern Theory (Schram \& Emerson, 1991).

(1) Cellular organization is of secondary importance in establishing the zootype. For example, one can directly compare the process of segmentation in Drosophila, which occurs in a syncytial blastoderm with a rapid diffusion of morphogens, to that in the flour beetle Tribolium, even though part of the latter's development occurs in a cellular, rather than syncytial, context (Sommer \& Tautz, 1993).

(2) Specific cell lineage is often irrelevant. For example, one can see this in the segmental repatterning of post-naupliar material (both ecto- and mesodermal) in peracarid crustaceans after a very regular unfolding of cell lineage up to that point (Dohle \& Scholz, 1988). Cell lineage is also scarcely relevant for the patterning of the central nervous system in the zebrafish (Kimmel, 1993). Furthermore, Weygoldt (1979) even questioned D.T. Anderson's (1973) contention that blastoderm fate maps had any relevance to discerning germ layer derivation, although Wheeler et al. (1993) believed Anderson's ontogenetic data had validity but only as a single multivariate feature among many others.

(3) The formation of body segments is not of primary importance. This has been examined above for arthropods (Jacobs, 1990; Schram \& Emerson, 1991). These authors contended that in phylogenetic as well as in developmental terms the heteronomously segmented animals are formed through the segmentation or the breakup of an earlier evolved body pattern, rather than a patterning or a 
regionalization of a previously segmented body. However, some steps in segmentation are sometimes anticipated during ontogeny, e.g., in the parasegments of Drosophila (Martinez Arias \& Lawrence, 1985) and corresponding units in chilopod centipedes (Minelli \& Bortoletto, 1988). Moreover, secondary patterning is sometimes superimposed at later developmental stages.

(4) Most animals are more extensively patterned ventrally than dorsally. The functional meaning of this is not difficult to understand given the sensory interactions with the substrate to achieve feeding and locomotion, but the morphogenetic control of this needs closer investigation. However, there exist several possible mechanisms to explain this, as seen in the complexity of the genetic control of dorsoventral polarity as known in Drosophila (K.V. Anderson, 1989), as well as theoretical models to explain this, as seen in explanations of the evolution of invertebrate form (Nielsen, 1985).

(5) Maternal control never extends over the full deployment of the zootype (Slack et al., 1993; Buss, 1988; Lawrence, 1992). The maternal genes serve to determine zygote polarities, but specific control of individual form falls largely to zygotic gene complexes.

(6) Body regions are almost always few in number. Why this is so remains obscure, but the fact remains that numbers of body regions seem to fall mostly between 2 and 4 .

(7) There is a stabilizing effect derived from the establishment of control over the posterior end of the body. The overlapping fields of control that radiate from the opposite ends, anterior and posterior, exist as a valuable pre-condition for the development of size-invariant patterns (cf. the French flag model of positional information developed by Wolpert, 1969; also, see below concerning the malacotype).

(8) Body landmarks (hot spots) have priority. By this we mean that the hot spot has multi-potentialities in phylogeny and ontogeny. Once established, the spots constrain the site of appearance of subsequent morphological events, whatever they might be. Four examples can illustrate this point. First, in planarians and digenean trematodes we can recognize a mid-body hot spot where either a mouth, or genital openings, or both can appear. Second, in nematodes, the subterminal hot spot marks cloacal openings in males but an anus only in females, the female genital pore being borne on an additional mid-body hot spot. Third, in tracheate arthropods (millipedes and insects) the same hot spot may be the site of either gonopore or secondary penis, as mentioned above. Fourth, an anterior mid-ventral hot spot apparently contrains the location of nephridiopores in echiurans as well as the anus in sipunculans.

(9) Terminal (apical) control has something to do with individuality. In forms that we believe lack effective terminal control, individuality is softened. Two examples can illustrate this. First, in scyphozoans, annular constrictions (types of hot spots) lead to strobilization. Second, in polypoid cnidarians, bryozoans, and certain protochordates, budding leads to colony formation. The manner of genetic control, or lack thereof, of these phenomena needs examination in detail.

(10) There is a minimum size for pattern expression. This size, however, depends on the patterning mechanism. For example, subcellular kineties act as templates to determine the ciliary structures in ciliate protistans (Frankel, 1989). However, for the kind of patterns we concern ourselves with here, some animals appear too small to get more than antero/posterior polarity, e.g., dicyemid mesozoans. Others seem too small to develop segmentation, e.g., eriophyid mites (ca. $50 \mu \mathrm{m}$ ).

(11) The function of specific anatomical structures stabilizes (reinforces) pattern. This seems true both for the anterior-posterior and dorsal-ventral polarities as well as for the positioning of landmarks (hot spots) along the main body axis.

\section{Selected phylotypes}

Given the above principles, and in the light of the phylotype concept (Slack et al., 1993; Seidel, 1960), we can suggest some specific phylotypes for which developmental geneticists need to search for the underlying genetic controls. We do not intend here to put forth a detailed analysis of all metazoans. However, we can indicate a few obvious types 


\begin{tabular}{|l|} 
lab pb Dfd Scr Ubx AbdB eve \\
ems
\end{tabular}
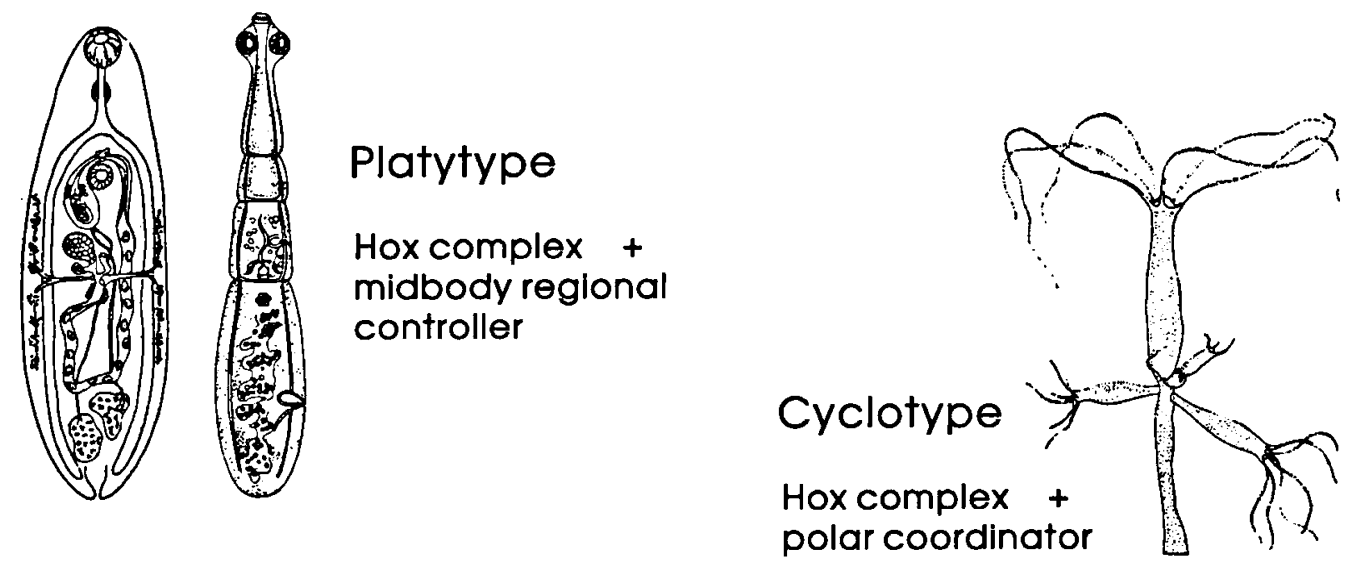

Platytype

Hox complex + midbody regional controller

Malacotype Hox complex + posterior terminator control
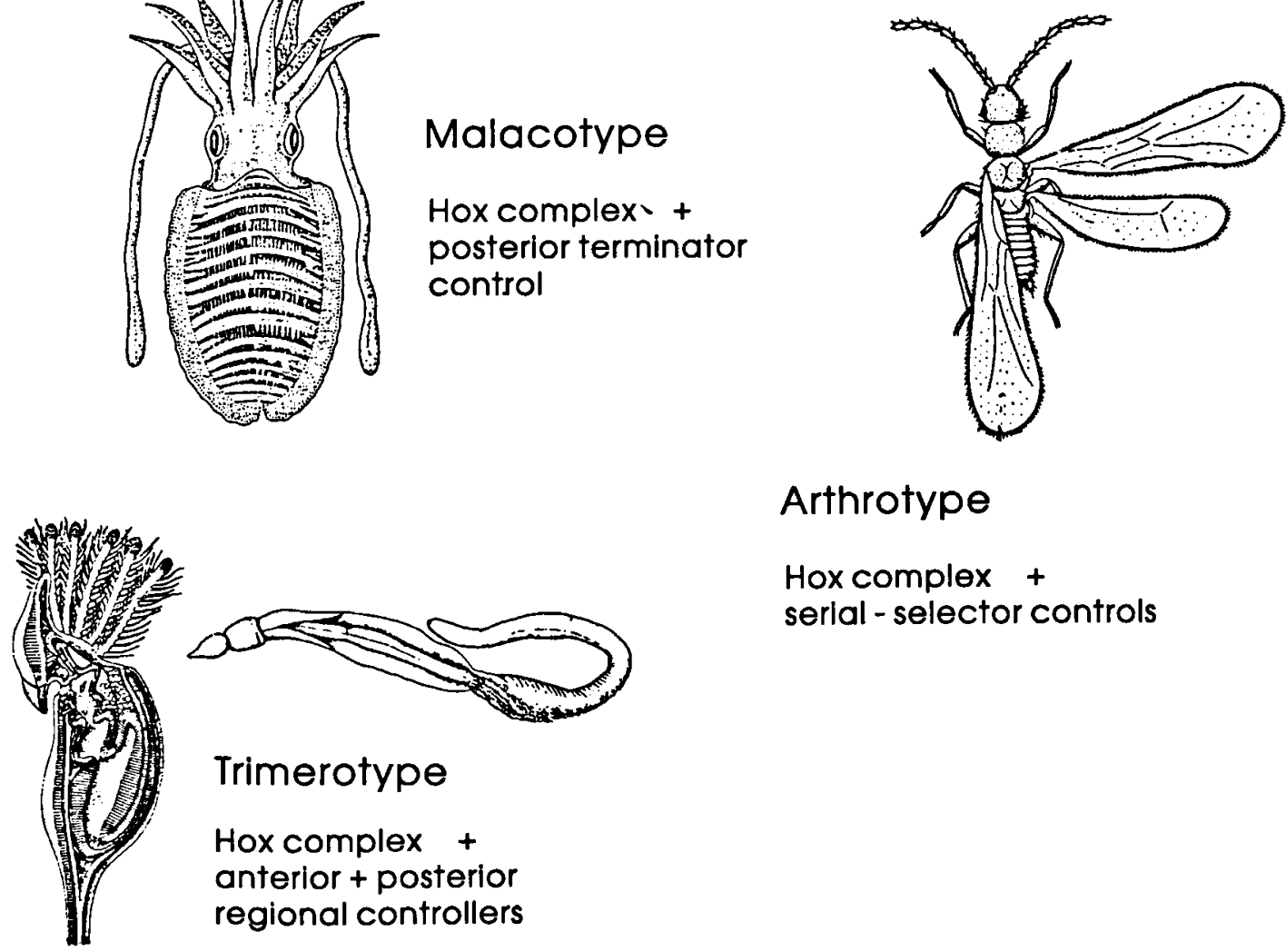

Trimerotype

Hox complex + anterior + posterior regional controllers

Hox complex +

serlal - selector controls

Arthrotype

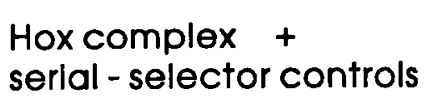


(Fig. 2). Furthermore, we do not expect that each phylum corresponds to a phylotype. Phylotypes are really better equated with levels or degrees of organization within the zygote and early developmental stages, and we would expect our phylotypes in some cases to correspond to grades rather than to clades.

We have already alluded to the control of arthropod body pattern postulated by Schram \& Emerson (1991). This pattern appears related to the operation of gap and homoeotic gene complexes (Averof \& Akam, 1993). Genetic specification of an "arthrotype" should come when developmental genetic studies expand beyond insects to include myriapods, crustaceans, and cheliceriforms. Some things to look for in this regard might include genetic markers of positional homology as well as terminal markers. This latter kind of marker should have significance for limb formation as well as for the main body. There appears to be an element of a polar coordinate reference system (Bryant, 1993) that operates in the development of arthropod appendages (perhaps only analogous to consideration of similar polar axis issues in the body of cnidarians). This polar system is coupled with a "segmentation" process similar to that of the main body axis of arthropods wherein protein markers of annulin mark the limb article boundaries (Bastiani et al., 1992; Steiner \& Keil, 1993). Limb development with clear limits to segment numbers on the limb seems to be generally coupled with strong apical or terminal control. Limb termini are often clearly demarcated by structural events (e.g., dactylar claws, terminal sensilla). When these terminal controls seem lacking, often segmental controls soften and flagellar ("ultra-segmented") limbs appear, e.g. malacostracan crustacean antennules, scutigeromorph centipede antennae and tarsi, and amblypygid chelicerate "pedipalps". Study of arthropods certainly will continue to play an important role in generating raw data relevant to a general theory of morphology.

Other phylotypes can be suggested. The Cnidaria and Ctenophora appear to possess the classic zootype as defined by Slack et al. (1993). However, given that the zootype specifies a dorso/ventralanterior/posterior orientation, the radiate Bauplan, or "cyclotype", of these phyla is somewhat at odds with the supposed underlying control that Slack et al. postulate. There is an implicit longitudinal orientation to their body plan with incipient hot spots that may correspond to sites of budding (already alluded to above). However, there also seems to be an additional polar coordinate reference system established in these animals that facilitates intercalary growth and structural development. This suppression of linearity may be linked with the absence of any strong terminal control of the body in these "lower" radiate forms.

A "platytype", around which flatworms evolved, clearly expresses the underlying zootype with distinct anterior-posterior, dorsal-ventral, and leftright orientation. While body regionalization seems incipient, these animals evidently lack a well-developed posterior controller. A mid-body hot spot, for which geneticists might seek a marker, acts as the locus of mouth and/or genital structures. In forms in which these features shift anteriorly, such as the catenulids, secondary events of constriction and budding take place at the mid-body hot spot. Moreover, the lack of effective posterior terminal control may allow the "paracolonial" strobilization of cestodes.

A "malacotype" affords an excellent example of

Fig. 2. Some tentatively postulated additional phylotypes as derived from the ideas of Slack et al. (1993). Their zootype consists of a distinct genetic component (the Hox complex) that defines the basic polarity of the metazoan zygote. Subsequently evolved diagnostic features are sketched in terms of elements of developmental control giving rise to "hot spots" located at different places along the main body axis. Some real animals are figured for reference Hydra (Cnidaria) for the cyclotype; a generic trematode (left) and the tapeworm Echinococcus (Cestoda) - this one with the body articulated into a short chain of units by a process of strobilization-for the platytype; Sepia (Mollusca) for the malacotype, Zorotypus (Insecta) for the arthrotype, and the polyp-like Cephalodiscus and the worm-like Balanoglossus (both Hemichordata) for the trimerotype. Abbreviations: otd-orthodenticle, ems-empty spiracles, lab-labial, pbproboscipedia, Dfd-deformed, Scr-sex combs reduced, Ubx-antennapedia/ultrabithorax/abdominal A group, AbdB-abdominal B, eve-even-skipped. 
what an effective posterior terminal controller produces, for this appears as the hallmark of the nemertine and molluscan Baupläne. This posterior controller expresses itself initially with the development of an anus, as in nemertines, and later on with the body terminus serving as the focus of excretory, respiratory, reproductive, and circulatory structures as in molluscs. Indeed, the structural constraint of a strong posterior controller may have proved too strict for the molluscs, in terms of function, since subsequent evolutionary events within the molluscs seem to focus on mitigating the effects of the posterior controller (and the concomitant lack of intermediate hot spots where new features could attach). Several alternative plans derive from this: 1) developing secondary hot spots, thus achieving "soft segmentation," as in polyplacophorans and monoplacophorans; 2) becoming strongly asymmetrical, as in gastropods; 3 ) shortening (monoplacophorans) and bending the body axis (cephalopods).

Finally, a "trimerotype" may have significance for several phyla. This plan focuses around a manifestation of two strong hot spots between the anterior and posterior controllers. Within the confines of this constraint, great variation exists with the expression of lophophorate, deuterostome, and certain aspects of trochophorate body plans. It is possible that certain aspects of this phylotype appeared independently within the higher phyla, but it seems clear that it is often subjected to some profound modifications. For example, we can note the effects of the imposition of a secondary polar coordinate system over the trimery of echinoderms, and the modification of or total lack of terminal control seen in the colonial lophophorates, hemichordates, and chordates.

\section{Conclusions}

The overall, most important feature in all of the above-mentioned phylotypes is the importance of the genetic control of timing of ontogenetic events, which reflects the phyletic evolution of metazoan body plans. The broad features of animal architecture, such as the anterior and posterior termini, and the hot spots between them, are under genetic and/ or some degree of epigenetic control. However, the development of specific structures probably retains a large degree of epigenetic autonomy. The appearance of anatomical features becomes functionally integrated into the animal body as a whole, but central control over their development persists mainly as a control of timing rather than as a control of specific form, e.g. endocrine involvement in the form of appendages developing from insect imaginal discs (Couso et al., 1993). We can now speak (indeed, we must speak, see Young, 1993) of animal "types" not with reference to abstract "paper animals", but rather with reference to specific gene complexes and timing sequences.

The science of morphology has come full circle. The great morphologists of the late 18th and early 19th century such as Cuvier, Geoffroy Saint-Hilaire, Goethe, and Owen, studied the broad patterns of animal structure and strove for generalizations as to the meanings of observed similarity in form and function. The typological concepts of this philosophie anatomique, especially those of Geoffroy St.Hilaire, provided an effective tool within a theoretical framework for directing morphological research (Russell, 1916). The great body of knowledge these scientists uncovered attests to the success of their method, knowledge that has effectively burrowed and cemented itself into the very foundations of modern biology. The perspective of that time viewed science and philosophy as parts of a continuum of human thought. Although western science came to reject the platonic philosophic aspects, the Naturphilosophie, of many of these early workers, it could not reject the discoveries they made (Young, 1993). These early morphologists worked in a time when "philosophical systems" determined that a major effort to establish a coherent body of theory should direct the course of future empirical investigations. The subsequent period, that which began with the efforts of Darwin and Wallace to establish a causal evolutionary theory, directed the attention of science away from a consideration of pattern and eventually compelled investigations of process that were much more experimentally oriented (Lenoir, 1982). These later day empiricists rejected the older morphologi- 
cal theory on grounds spurious to its proven efficacy, and as a result morphological investigations passed into eclipse. Even today, investigators often view analyses of pattern as somehow less important, even less "scientific", than those of process. With the 150th anniversary of Owen's definition of homology, we believe the time has come to redress this imbalance.

\section{Acknowledgements}

This research has obtained partial support from grants from the Italian National Research Council (C.N.R.) and the Italian Ministry of the University and Scientific and Technological Research (MURST) to A.M.

\section{References}

Alberch, P., S.J. Gould, G.F. Oster \& D.B. Wake, 1979. Size and shape in ontogeny and phylogeny. Paleobiol., 5: 296317.

Anderson, D.T., 1973. Embryology and phylogeny in annelids and arthropods: 1-495 (Pergamon Press, New York).

Anderson, K.V., 1989. Drosophila: The maternal contribution. In: D.M. Glover \& B.D. Hames (eds.), Genes and embryos: 1-37 (IRL at Oxford Univ. Press, Oxford/New York/ Tokyo).

Averof, M. \& M. Akam, 1993. HOM/Hox genes of Artemia: implications for the origin of insect and crustacean body plans. Curr. Biol., 3: 73-78.

Bastiani, M.J., H.G. de Couet, J.M.A. Quinn, R.O. Karlstrom, K. Kotrla, C.S. Goodman \& E.E. Ball, 1992. Postion-specific expression of the annulin protein during grasshopper embryogenesis. Dev. Biol., 154: 129-142.

Bryant, P., 1993. The polar coordinate model goes molecular. Science, 259: 471-472.

Buss, L.W., 1988. The evolution of individuality: 1-201 (Princeton University Press, Princeton).

Conway Morris, S., 1993. The fossil record and the early evolution of the Metazoa. Nature, 361: 219-225.

Couso, J.P., M. Bate \& A. Martinez Arias, 1993. A winglessdependent polar coordinate system in Drosophila imaginal discs. Science, 259: 484-489.

Cuvier, G., 1817. Le règne animal distribué d'après son organisation, vol. 1: 1-540 (Déterville, Paris).

Dohle, W. \& G. Scholz, 1988. Clonal analysis of the crustacean segment: the discordance between genealogical and segmental borders. Development, 104 (Suppl.): 147-160.

Eernisse, D.J., J.S. Albert \& F.E. Anderson, 1992. Annelida and Arthropoda are not sister taxa: A phylogenetic analysis of spiralian metazoan morphology. Syst. Biol., 41: 305-330.

Emerson, M.J. \& F.R. Schram, 1990. The origin of crustacean biramous appendages and the evolution of Arthropoda. Science, 250: 667-669.

Frankel, J., 1989. Pattern formation. Ciliate studies and models: 1-314 (Oxford Univ. Press, New York).

Geoffroy Saint-Hilaire, É., 1818-22. Philosophie anatomique: 1-517 (J.B. Baillière, Paris).

Gould, S.J., 1977. Ontogeny and phylogeny: 1-501 (Belknap Press, Cambridge, Mass.).

Gupta, A.P. (ed.), 1979. Arthropod phylogeny: 1-762 (Van Nostrand Reinhold, New York).

Holland, P., 1992. Homeobox genes in vertebrate evolution. BioEssays, 14: 267-273.

Jacobs, D.K., 1990. Selector genes and the Cambrian radiation of Bilateria. Proc. natl. Acad. Sci., 87: 4406-4410.

Kimmel, Ch.B., 1993. Patterning the brain of zebrafish embryo. Ann. Rev. Neurosciences, 16: 707-732.

Lawrence, P.A., 1992. The making of a fly: 1-228 (Blackwell, Oxford).

Lenoir, T., 1982. The strategy of life: 1-314 (D. Reidel, Dordrecht).

Manton, S.M., 1977. The Arthropoda: 1-527 (Clarendon Press, Oxford).

Martinez Arias, A. \& P. Lawrence, 1985. Parasegments and compartments in the Drosophila embryo. Nature, 313: 639642.

Meglitsch, P.A. \& F.R. Schram, 1991. Invertebrate zoology, 3rd edition: 1-623 (Oxford University Press, New York).

Minelli, A., 1992. Towards a new comparative morphology of myriapods. Ber. nat.-med. Ver. Innsbruck, 10 (Suppl.): 3746.

Minelli, A. \& S. Bortoletto, 1988. Myriapod metamerism and arthropod segmentation. Biol. J. Linn. Soc. Lond., 33: 323343.

Nielsen, C., 1985. Animal phylogeny in the light of the trochea theory. Biol. J. Linn. Soc. Lond., 25: 243-299.

Owen, R., 1843. Lectures on the comparative anatomy of invertebrates (Longmans, Brown, Green, and Longman, London).

Roth, V.L., 1988. The biological basis of homology. In: C.J. Humphries (ed.), Ontogeny and systematics: 1-26 (British Museum (Natural History), London).

Russell, E.S., 1916. Form and function: 1-383 (John Murray, London).

Schram, F.R., 1986. Crustacea: 1-606 (Oxford University Press, New York).

Schram, F.R., 1991. Cladistic analysis of metazoan phyla and the placement of fossil problematica. In: A.M. Simonetta \& S. Conway Morris (eds.), The early evolution of Metazoa and the significance of problematic taxa: 35-46 (Cambridge University Press, Cambridge).

Schram, F.R. \& M.J. Emerson, 1991. Arthropod pattern theory: a new approach to arthropod phylogeny. Mem. Queensland Mus., 31: 1-18.

Seidel, F., 1960. Körpergrundgestalt und Keimstruktur. Eine 
Erörterung über die Grundlagen der vergleichenden und experimentellen Embryologie und deren Gültigkeit bei phylogenetischen Überlegungen. Zool. Anz., 164: 245-305.

Slack, J.M.W., P.W.H. Holland \& C.E. Graham, 1993. The zootype and the phylotypic stage. Nature, 361: 490-492.

Sommer, R.J. \& D. Tautz, 1993. Involvement of an orthologue of the Drosophila pair-rule gene hairy in segment formation of the short-band embryo of Tribolium (Coleoptera). Nature, 361: 448-458.

Steiner, C. \& T.A. Keil, 1993. Morphogenesis of the antenna of the male silkmoth, Antheraea polyphemus. IV. Segmentation and branch formation. Tissue and Cell, 25: 447-464.

Weygoldt, P., 1979. Significance of later embryonic stages and head development in arthropod phylogeny. In: A.P. Gupta (ed.), Arthropod phylogeny: 107-135 (Van Nostrand Reinhold, New York).

Wheeler, W.C., P. Cartwright \& C.Y. Hayashi, 1993. Arthropod phylogeny: a combined approach. Cladistics, 9: 1-39.

Wolpert, L., 1969. Positional information and the spatial pattern of cellular differentiation. J. theor. Biol., 25: 1-47.

Young, B.A. 1993. On the necessity of an archetype concept in morphology: with special reference to the concepts of "structure" and "homology". Biology and Philosophy, 8: 225248.

Received: 26 November 1993 